\title{
Dot-immunobinding assay with monoclonal antibody for detection of Trichomonas vaginalis in clinical specimens
}

\author{
A Gombošová, $M$ Valent
}

\begin{abstract}
A rapid and specific dot-enzyme immunoassay (DIBA) using monoclonal antibody was introduced for detection of Trichomonas vaginalis antigen in vaginal and urethral materials. The results of DIBA were compared with culture findings of the parasite in 245 female patients. Taking culture as the reference method, DIBA had a sensitivity of $92 \%$ and a specificity of $93 \%$. The predictive value of a positive test was $98 \%$ and that of a negative test $77 \%$. The efficacy of wet mount, culture and DIBA were compared in 134 women with trichomonal infection. The most sensitive method was cultivation with a positivity of $99 \cdot 3 \%$. DIBA was as sensitive as the wet mount $(92 \%)$. In 51 sexual partners of women with trichomoniasis DIBA proved to be ineffective. The sensitivity of the assay with corpuscular antigen of $T$ vaginalis was $1 \times 10^{4}$ cells/ml, with soluble antigen $47 \mu \mathrm{g} / \mathrm{ml}$. Specificity of the assay was confirmed by lack of any cross-reactivity with Trichomonas tenax, Tritrichomonas mobilensis and Candida albicans.
\end{abstract}

Trichomoniasis is a worldwide common sexually transmitted disease. The causative agent, Trichomonas vaginalis has for long been regarded as a relatively benign parasite of the genitourinary system. Recent reports of the interaction of this protozoon with bacteria and viruses, ${ }^{12}$ however, point on its possible role in transmission of more serious pathogens to deeper parts of genital organs.

Despite efficient therapy the incidence of trichomoniasis remains rather high. The main reason is the frequent asymptomatic course of infection. These cases escape diagnosis and therapy and serve as potential sources for spreading the disease in

The Institute of Parasitology of Comenius University, Bratislava, Czechoslovakia

A Gombošová, $M$ Valent population. Therefore a need for a simple, rapid and inexpensive screening method becomes increasingly important. Serodiagnostic methods have not proven effective for this purpose. ${ }^{3-5}$ Immunofluorescence and ELISA for antigen detection ${ }^{6-9}$ are essentially laboratory tests, not suitable for epidemiological studies. The latex-agglutination test ${ }^{10}$ is not very useful with vaginal secretions, as the curd-like discharge in vaginal candidiasis ${ }^{11}$ may mimic a positive reaction.

The aim of this study was to evaluate the suitability of dot-blot immunoassay for screening trichomoniasis in female and male populations.

\section{Material and methods \\ Patients}

Two hundred and forty five female outpatients attending the Institute of Parasitology were included in the study. The age ranged between 16 and 64 years (mean 34). Clinical symptoms (discharge, itching, burning, pelvic pain) were present in 178 women; 67 were asymptomatic. Material for wet-mount microscopy, culture and dot-immunobinding assay (DIBA) was obtained during pelvic examination from the posterior fornix of the vagina.

Fifty five sexual partners of women with positive cultivation finding of $T$ vaginalis were also examined. Specimens from the distal urethra and the sediment of the morning urine were examined by microscopy, culture and DIBA.

\section{Sample collection}

The material from the vagina and urethra for wet mount was taken with bacteriological loop to a drop of sterile saline on a microscope slide and evaluated immediately for the presence of motile parasites by phase contrast microscopy at $\times 200$ magnification. Urine sediment examination was performed the same way. For cultivation, swabs from the vagina and urethra were collected directly into $10 \mathrm{ml}$ of modified Diamond's medium TYM ${ }^{12}$ supplemented with $10 \%$ bovine serum, $1000 \mathrm{IU} / \mathrm{ml}$ penicillin and $1 \mathrm{mg} / \mathrm{ml}$ streptomycin. Culture tubes were examined microscopically for motile parasites after 24 and 72 hour incubation at $37^{\circ} \mathrm{C}$. 
Swabs taken for antigen detection were broken off into $1 \mathrm{ml}$ phosphate-buffered saline (PBS) and centrifuged at $800 \times g$ for $5 \mathrm{~min}$. Urine samples were processed at the same time. The supernates were stored at $-20^{\circ} \mathrm{C}$ until tested. In some experiments the squares of nitrocellulose were soaked into the discharge left on the vaginal speculum after gynaecologic examination.

\section{Preparation of $T$. vaginalis antigen}

Laboratory strains DD-3 and $K-1^{13}$ cultured in Diamond's medium TYM without agar, in logarithmic growth phase (24 hours), were washed three times in PBS ( $800 \times g, 5 \mathrm{~min})$ and either used immediately as corpuscular antigen, or the pellet was resuspended in PBS and frozen and thawed 10 times $\left(-20^{\circ} \mathrm{C}, 20^{\circ} \mathrm{C}\right)$. After centrifugation $(3000 \times \mathrm{g}, 60$ $\min , 4^{\circ} \mathrm{C}$ ) the soluble fraction was assayed for protein contents by the Lowry method ${ }^{14}$ and stored in aliquots at $-20^{\circ} \mathrm{C}$. Strains of T. tenax B-1 (kindly provided by Dr Kulda, Charles University, Prague), $T$. mobilensis USA:M776 (obtained through the courtesy of Dr Gardner, University of South
Alabama) and Candida albicans (isolated on Sabouraud agar from a patient with candidal vaginitis) were processed as the corpuscular antigen of $T$. vaginalis.

\section{Monoclonal antibody}

A mouse monoclonal antibody DM 116 was purchased from Dr Alderete (University of Texas). This IgGl immunoglobulin reacted with a 65 kilodalton surface polypeptide of $T$. vaginalis. ${ }^{15}$ Concentration of proteins of the hybridoma supernate was $5 \mathrm{mg} / \mathrm{ml}$ and it was used undiluted in DIBA experiments.

\section{DIBA procedure}

A strip of nitrocellulose, moistened in deionised water was divided on squares by pencil lines. Two $\mu \mathrm{l}$ of examined material was applied to each square. After drying in air, the strips were incubated in a Petri dish with PBS containing $5 \%$ bovine serum albumin (PBS-BSA) either for one hour at room temperature or overnight at $4^{\circ} \mathrm{C}$. The strips were briefly rinsed in PBS and incubated with monoclonal antibody for $30 \mathrm{~min}$ at $20^{\circ} \mathrm{C}$ by constant shaking.

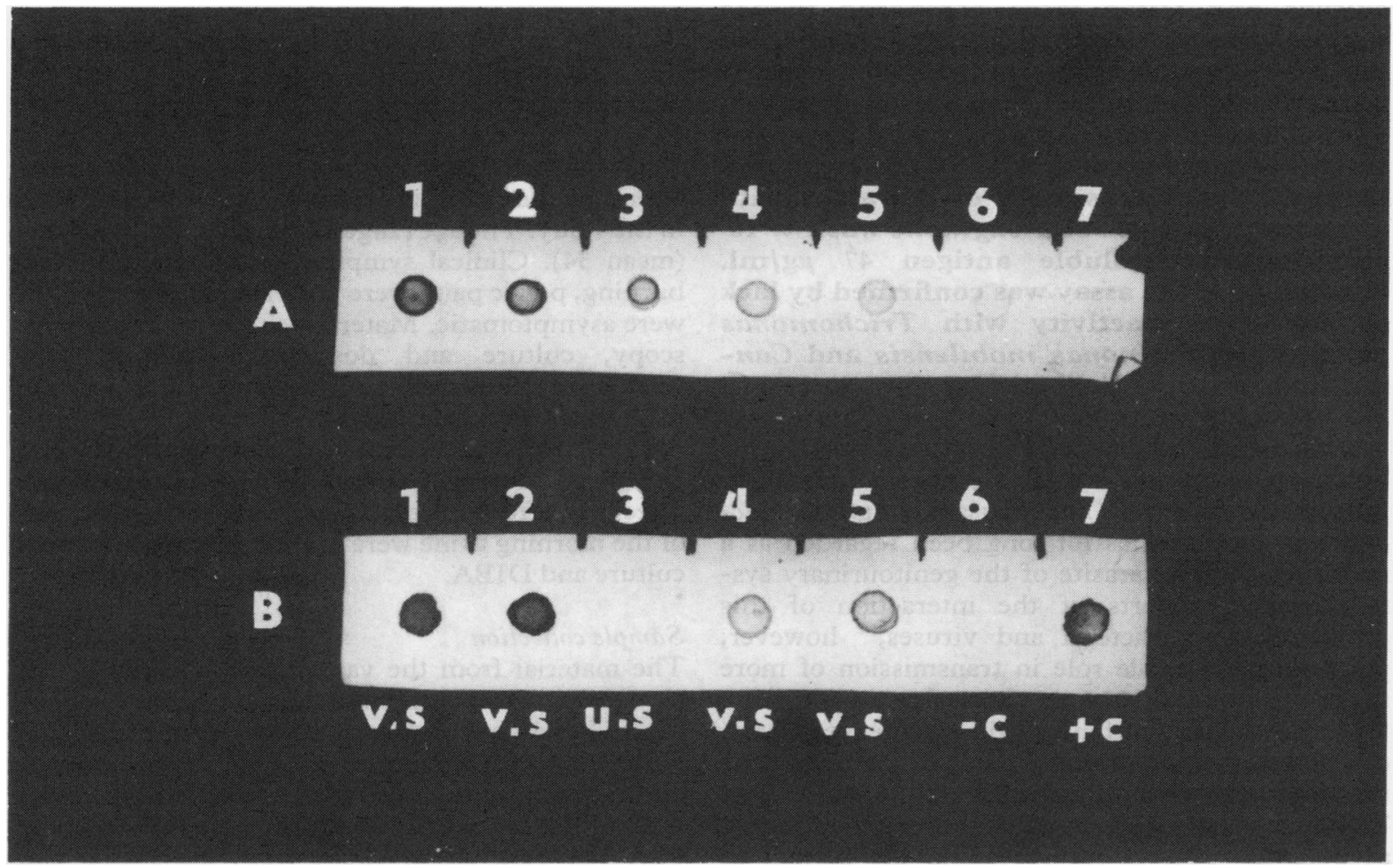

Figure A-Titration of soluble antigen of $T$. vaginalis (1.5 mg protein per $\mathrm{ml}$ ) serially diluted in PBS and applied to nitrocellulose in $2 \mu \mathrm{l}$ volume. The reaction is positive up to the dilution of $1: 32(47 \mu \mathrm{g} / \mathrm{ml})$.

$B$-Detection of $T$. vaginalis antigen by DIBA in vaginal swab eluates (v.s) of women with trichomoniasis and in urethral swab eluate (u.s) of a sexual partner of one of the patients. Supernates of the eluates were applied to the nitrocellulose in $2 \mu l$ volumes. Positive reaction-vaginal swabs (Nos 1, 2, 4, 5), negative reaction-urethral swab (No 3). No 6-negative control (pool of eluates of vaginal swabs of ten healthy volunteers), No 7-positive control(soluble antigen of T. vaginalis; $1.5 \mathrm{mg}$ protein per $\mathrm{ml}$ ). 
Table 1 Results of cultivation and DIBA determination of $T$. vaginalis in vaginal material of 245 women

\begin{tabular}{|c|c|c|}
\hline \multicolumn{2}{|c|}{ Result of detection method } & \multirow[b]{2}{*}{ Number of specimens (\%) } \\
\hline Cultivation & $D I B A$ & \\
\hline $\begin{array}{l}\text { Positive } \\
\text { Positive } \\
\text { Negative } \\
\text { Negative } \\
\text { Total }\end{array}$ & $\begin{array}{l}\text { Positive } \\
\text { Negative } \\
\text { Positive } \\
\text { Negative }\end{array}$ & $\begin{array}{rr}175 & (71 \cdot 5) \\
16 & (6 \cdot 5) \\
4 & (1 \cdot 6) \\
50 & (20 \cdot 4) \\
245 & (100 \cdot 0)\end{array}$ \\
\hline
\end{tabular}

After being rinsed with PBS $(3 \times 5 \mathrm{~min})$ the strips were incubated with swine anti-mouse immunoglobulin conjugated with peroxidase (SwAMIg-Px, USOL, Prague) diluted 1:500 in PBS-BSA. After 30 min incubation at room temperature with constant agitating, the strips were rinsed again as above. The substrate $(0.5 \%$ 4-chloro-1-naphtol in $20 \%$ methanol with $0.5 \% \mathrm{H}_{2} \mathrm{O}_{2}$ ) was added and the strips were incubated for five minutes by constant shaking at room temperature, then briefly rinsed with distilled water and dried in air. The presence of $T$. vaginalis antigen was revealed by the blue staining in place of application of the sample (fig B). Soluble antigen of $T$. vaginalis (protein concentration $1.5 \mathrm{mg} / \mathrm{ml}$ ) was used as positive control in each test. A pooled supernatant of ten eluates of vaginal swabs obtained from healthy volunteers (negative cultivation finding of $T$. vaginalis) served as negative control.

\section{Results}

The sensitivity of DIBA was determined by testing various concentrations of corpuscular and soluble antigen of $T$. vaginalis. The reaction was positive to a concentration of $10^{4}$ parasites $/ \mathrm{ml}$, which is a concentration generally regarded as a detection limit of wet mount preparation. With soluble antigen the sensitivity was $47 \mu \mathrm{g} / \mathrm{ml}$ (fig A).

To test the specificity of DIBA, the assay was performed with laboratory strains of $T$. tenax, $T$. mobilensis and Candida albicans. No cross-reactivity was observed with either strain in the range of tested concentrations $\left(10^{1}-10^{8}\right.$ cells $\left./ \mathrm{ml}\right)$.

\section{Clinical samples}

The results of DIBA for the presence of $T$. vaginalis

Table 2 Comparison of three methods for detection of $T$. vaginalis infection in 134 women with trichomoniasis

\begin{tabular}{lll}
\hline \multirow{2}{*}{ Method } & \multicolumn{2}{l}{ Number of specimens (\%) } \\
\cline { 2 - 3 } & Positive & Negative \\
\hline Wet-mount & $123(91 \cdot 8)$ & $11(8 \cdot 2)$ \\
Cultivation & $133(99 \cdot 3)$ & $1(0 \cdot 7)^{\star}$ \\
DIBA & $123(91 \cdot 8)$ & $11(8 \cdot 2)$ \\
\hline
\end{tabular}

*In vaginal sample of this patient motile trichomonads were present in wet-mount preparation
Table 3 Efficacy of three diagnostic methods for the presence of $T$. vaginalis in urethral samples and urine of 51 sexual partners of trichomoniasis patients

\begin{tabular}{lcc}
\hline & \multicolumn{2}{c}{ Number of specimens (\%) } \\
\cline { 2 - 3 } Method & Positive & Negative \\
\hline Wet-mount & $8(16)$ & $43(84)$ \\
Cultivation & $14(27)$ & $37(73)$ \\
DIBA & 0 & $51(100)$ \\
\hline
\end{tabular}

antigen in vaginal specimens of 245 women are summarised in table 1 and compared with the culture findings. Identical results with both methods were obtained in $225(92 \%)$ clinical samples, sixteen were considered false negatives and in four cases positivity in DIBA occurred along with negative culture finding. The sensitivity of DIBA was $92 \%$, specificity $93 \%$, the predictive value of a positive result was $98 \%$ and that of a negative result $77 \%$.

In a group of 134 female patients with trichomoniasis, the diagnostic efficacy of DIBA was compared with those of wet mount preparation and cultivation (table 2). Culture proved to be the most effective from the three methods. Only one patient, positive in wet mount preparation had negative culture of the parasite. The DIBA result in this case was positive. Efficacy of DIBA and of microscopic examination was the same $(92 \%)$. The results obtained by both methods were identical in 117 patients. In six women, negative in DIBA, only single trichomonads were present in wet mount preparations. By microscopic examination of vaginal samples of the six women, positive in DIBA, abundant cells of trichomonads (by shape) were observed. As these cells were not motile, the microscopic finding was evaluated as negative. Culture in these cases was unsuccessful.

Detection of the parasite in 51 sexual partners of women with laboratory-proved trichomoniasis was low by either method (table 3 ). DIBA reaction proved to be an ineffective diagnostic tool in men, as no positivity was recorded either in samples from the urethra or in the urine.

\section{Discussion}

Although the need for a rapid and sensitive diagnostic test for trichomoniasis has increased in recent years, none of the existing diagnostic methods has proved suitable for broad epidemiological surveys. The disadvantage of wet mount, currently the most rapid and inexpensive method, ${ }^{16}$ is the need of a microscope and the fact that it has to be performed immediately after collecting the material during gynaecologic examination. Immunofluorescence and ELISA are more expensive methods. For evaluating a large number of specimens by ELISA a certain 
degree of automation is necessary. The dot-immunobinding technique, though widely used in diagnostics of other sexually transmitted diseases, ${ }^{17} 18$ has not been used for trichomoniasis up to now. In our study this method proved to be of sensitivity equal to the most frequently used wet mount preparation. Its advantage is the ability to detect the organisms with impaired or ceased motility, or even dead parasites. Similar to the latex-agglutination test, ${ }^{10}$ this method is able to detect soluble as well as corpuscular antigen, and requires no apparatus or training of the personel. The cheese-like discharge in yeast infection, which may imitate the positive reaction in latex-agglutination test, cannot interfere in dot-immunobinding assay.

As this test may be performed independently from the clinical examination of the patients, it seems particularly appropriate for broad epidemiological screenings of trichomoniasis among women. In men, however, the concentration of the parasite most probably is not sufficient to be detected either by this, or by any of existing immunological methods. ${ }^{19}$

Address for correspondence: Anna Gombošová, Institute of Parasitology, Comenius University, Palisády 40, 81106 Bratislava, Czechoslovakia.

1 Street DA, Wells C, Taylor-Robinson D, Ackers JP. Interaction between Trichomonas vaginalis and other pathogenic microorganisms of the human genital tract. $\mathrm{Br} J$ Venereal Dis 1984;60:31-8.

2 Pindak FF, Mora De Pindak M, Hyde BM, Gardner WA. Acquisition and retention of viruses by Trichomonas vaginalis. Genitourin Med 1989;65:366-71.

3 Mason PR. Serodiagnosis of Trichomonas vaginalis infection by the indirect fluorescent antibody test. J Clin Pathol 1979; 32:1211-5.

4 Street DA, Taylor-Robinson D, Ackers JP, Hanna NF, McMillan A. Evaluation of an enzyme-linked immunosorbent assay for the detection of antibody to Trichomonas vaginalis in sera and vaginal secretions. Br J Venereal Dis 1982;58:380-3.

5 Satapathy G, Kar SK, Samantaray JC, Panda SK. Trichomonas vaginitis: evaluation of serological tests and identification of immunoreactive surface peptides. Genitourin Med 1988; 64:110-4.

6 Krieger JN, Tam MR, Stevens CE, et al. Diagnosis of trichomoniasis. Comparison of conventional wet mount examination with cytologic studies, cultures and monoclonal antibody staining of direct specimens. JAMA 1988;259:1223-7.

7 Watt RM, Philip A, Wos SM, Sam GJ. Rapid assay for immunological detection of Trichomonas vaginalis. J Clin Microbiol 1986;24:551-5.

8 Yule A, Gellan MCA, Oriel JD, Ackers JP. Detection of Trichomonas vaginalis antigen in women by enzyme immunoassay. J Clin Pathol 1987;40:566-8.

9 Lisi PJ, Dondero RS, Kwiatkoski D, Spence M, Rein MF, Alderete JF. Monoclonal-antibody-based enzyme-linked immunosorbent assay for Trichomonas vaginalis. J Clin Microbiol 1988;26:1684-6.

10 Carney JA, Unadkat P, Yule A, Rajakumar R, Lacey CJN, Ackers JP. New rapid latex agglutination test for diagnosing Trichomonas vaginalis infection. J Clin Pathol 1988;41:806-8.

11 Hume JC. Trichomoniasis, candidiasis and Gardnerella vaginalis vaginitis as sexually transmitted diseases. Dermatol Clin 1983;1:137-51.

12 Diamond LS. The establishment of various trichomonads of animals and man in axenic cultures. $J$ Parasitol 1957;43: 488-90.

13 Alderete JF, Demeš $P$, Gombošová $A$, et al. Specific parasitism of purified vaginal epithelial cells by Trichomonas vaginalis. Infect Immun 1988;56:2558-62.

14 Lowry OH, Rosenbrough NJ, Farr AL, Randall RJ. Protein measurement with Folin phenol reagent. J Biol Chem 1951; 192:265-75.

15 Alderete JF, Demeš P, Gombošová A, et al. Phenotypes and protein-epitope phenotypic variation among fresh isolates of Trichomonas vaginalis. Infect Immun 1987;55:1037-41.

16 Lossick JG. The diagnosis of vaginal trichomoniasis. JAMA 1988;259:1230.

17 Lussier M, Brodeur BR, Winston S. Detection of Neisseria gonorrhoeae by dot-enzyme immunoassay using monoclonal antibodies. J Immunoassay 1989;10:373-94.

18 Patel JD, Joseph JM, Falkler WA. Direct detection of Chlamydia trachomatis in clinical specimens by a dot-immunobinding technique using monoclonal antibody. J Immunol Meth 1988; 108:279-87.

19 Wilson A, Ackers JP. Urine culture for the detection of Trichomonas vaginalis in men. Br J Vener Dis 1980;56:46-8.

Accepted for publication 3 September 1990 